\title{
DIFFERENT TYPES \\ OF ELECTRON-VIBRATIONAL INTERACTION IN BEDT-TTF SALTS WITH HALIDE-MERCURATE ANIONS STUDIED BY IR SPECTROSCOPY
}

\author{
M.G. Kaplunov and R.N. Lyubovskaya \\ Institute of Chemical Physics, Chernogolovka, Moscow Distr., 142432, Russia
}

Infrared optical properties of a large family of BEDT-TTF salts with mercury-halide anions are studied which exhibit different types of electron-vibrational spectra.

PACS numbers: $78.30 . \mathrm{Jw}$

\section{Introduction}

Some of the salts of bis(ethylenedithio)tetrathiafulvalene (BEDT-TTF or ET) exhibit superconductivity to $13 \mathrm{~K}$. A modified weak coupling BCS mechanism of superconductivity may be considered for these systems which include the effects of intramolecular vibrations [1,2]. Study of infrared optical properties is a good method for investigating electron-molecular vibrations interaction in organic conductors.

Salts of ET with halide-mercurate anions form a wide class of organic conductors with a variety of electrical properties (from dielectrics to superconductors) [3-9]. In this paper we present the results of the study of optical properties of a large family of such salts.

\section{Experimental}

The synthesis of the studied crystals is described elsewhere [3-8]. We measured the polarized reflectivity in the region of $300-5000 \mathrm{~cm}^{-1}$ for single crystals from the crystal plain containing conducting sheets of ET molecules. Reflectivity is measured for the two main optical directions in this plane, for which the largest difference between the two spectra is observed. 


\section{Results and discussion}

Typical reflectivity spectra of ET salts with halide-mercurate anions are given in Figs. 1, 2. Two types of IR reflectivity spectra may be considered from the given data. The typical representative of the type 1 may be the spectra of $\kappa$-phase structure superconducting compounds $(\mathrm{ET})_{4} \mathrm{Hg}_{3-\delta} \mathrm{X}_{8}(\mathrm{X}=\mathrm{Cl}, \mathrm{Br})$ [10-12] (Fig. 1a). This kind of spectra contains a characteristic group of electron-vibrational bands with main maxima at about 1250 and $1350 \mathrm{~cm}^{-1}$ and also bands at about 850 and $400 \mathrm{~cm}^{-1}$. These bands are attributed to electron-vibrational interaction involving totally symmetric intramolecular vibrational modes which is confirmed by theoretical analysis of IR spectra with the use of the "phase phonons" model [10-12].

The typical representative of compounds with type 2 spectra is a family $(\mathrm{ET})_{8}\left[\mathrm{Hg}_{2} \mathrm{X}_{6}\left(\mathrm{C}_{6} \mathrm{H}_{5} \mathrm{Y}\right)\right]_{2}(\mathrm{X}=\mathrm{Cl}, \mathrm{Br})$ (Fig. 2a). Such spectra do not contain vibrational peaks characteristic of the type 1 and exhibit only a weak broad hump in the region of $1000-1400 \mathrm{~cm}^{-1}$. This may be accounted for by including of non-totally symmetric vibrational modes in the process of the electron-phonon interaction, which is confirmed by the model calculations of reflectivity spectra for $(\mathrm{ET})_{8}\left[\mathrm{Hg}_{2} \mathrm{X}_{6}\left(\mathrm{C}_{6} \mathrm{H}_{5} \mathrm{Y}\right)\right]_{2}[14]$.

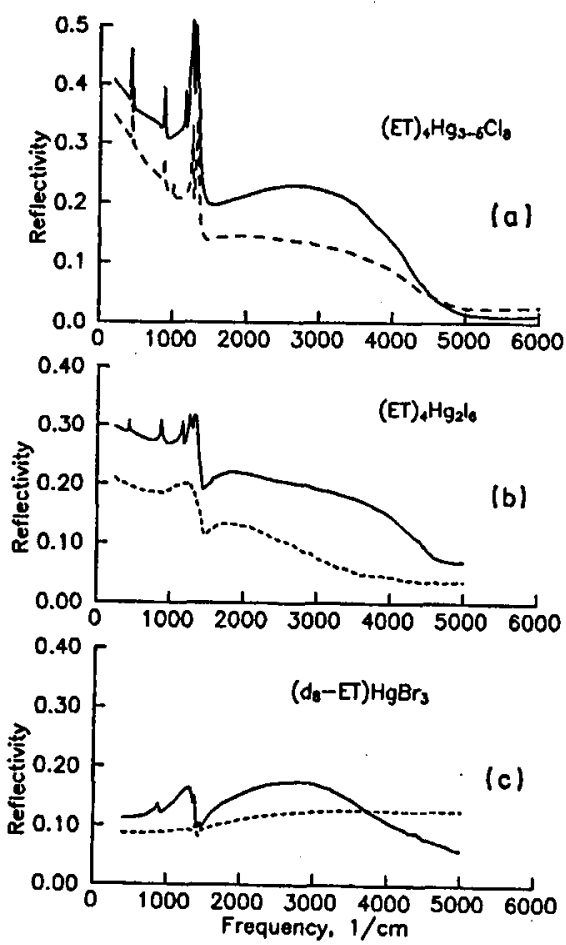

Fig. 1. Polarized reflectivity spectra of (a) (ET) $)_{4} \mathrm{Hg}_{3-\delta} \mathrm{Cl}_{8}$, (b) (ET) ${ }_{4} \mathrm{Hg}_{2} \mathrm{I}_{6}$ and (c) $\left(\mathrm{d}_{8}-\mathrm{ET}\right) \mathrm{HgBr}_{3}$. 

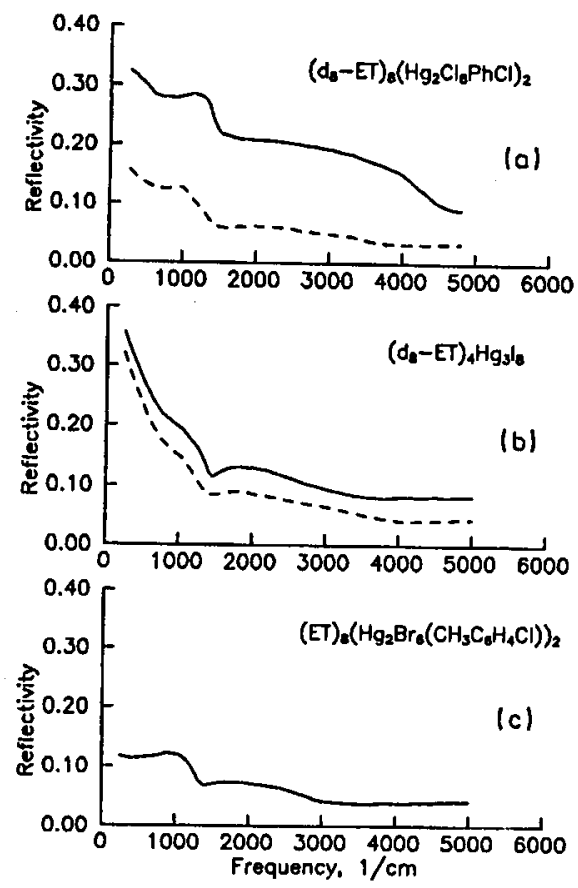

Fig. 2. Reflectivity spectra of (a) $\left(\mathrm{d}_{8}-\mathrm{ET}\right)_{8}\left[\mathrm{Hg}_{2} \mathrm{Cl}_{6}\left(\mathrm{C}_{6} \mathrm{H}_{5} \mathrm{Cl}\right)\right]_{2},(\mathrm{~b})\left(\mathrm{d}_{8}-\mathrm{ET}\right)_{4} \mathrm{Hg}_{3} \mathrm{I}_{8}$ (polarized) and (c) $(\mathrm{ET})_{8}\left[\mathrm{Hg}_{2} \mathrm{Br}_{6}\left(\mathrm{CH}_{3} \mathrm{C}_{6} \mathrm{H}_{4} \mathrm{Cl}\right)\right]_{2}$ (unpolarized).

The reason for involving of non-totally symmetric vibrational modes may be violation of molecular symmetry during the process of intermolecular charge transfer. This, in turn, may result from the "side-by-side" manner of intramolecular interaction due to shortened S...S contacts between side sulfur atoms of ET molecules which is characteristic of $(\mathrm{ET})_{8}\left[\mathrm{Hg}_{2} \mathrm{X}_{6}\left(\mathrm{C}_{6} \mathrm{H}_{5} \mathrm{Y}\right)\right]_{2}$ family $[4,14]$.

The spectra of semiconducting [5] (ET) ${ }_{4} \mathrm{Hg}_{3} \mathrm{I}_{8}$ belong to the type 2 (Fig. 2b). Its crystal structure contains sheets of ET molecules which interact mostly in "side-by-side" mode [5]. The crystal structure of (ET) ${ }_{4} \mathrm{Hg}_{2} \mathrm{I}_{6}$ reminds that of (ET) ${ }_{4} \mathrm{Hg}_{3} \mathrm{I}_{8}$ differing by doubling of one of periods and some details of molecular orientation [6]. In spite of this, the spectrum of this compound in one of polarizations is close to type 1 (Fig. 1b).

The type 2 spectra of $\left(\mathrm{d}_{8}-\mathrm{ET}\right)_{8}\left[\mathrm{Hg}_{2} \mathrm{Cl}_{6}\left(\mathrm{C}_{6} \mathrm{H}_{5} \mathrm{Cl}\right)\right]_{2}$ and $\left(\mathrm{d}_{8}-\mathrm{ET}\right)_{4} \mathrm{Hg}_{3} \mathrm{I}_{8}$ (Fig. 2a,b) are close to that of analogous protonated salts. This is in contrast with the type 1 spectra of $\kappa$-phase compounds, for which lack of resolution is observed in the region of $1200-1400 \mathrm{~cm}^{-1}$ for deuterated salts [13].

(ET) $)_{8}\left[\mathrm{Hg}_{2} \mathrm{Br}_{6}\left(\mathrm{CH}_{3} \mathrm{C}_{6} \mathrm{H}_{4} \mathrm{Cl}\right)\right]_{2}$ exhibits the type 2 spectrum like the compounds of $(\mathrm{ET})_{8}\left[\mathrm{Hg}_{2} \mathrm{X}_{6}\left(\mathrm{C}_{6} \mathrm{H}_{5} \mathrm{Y}\right)\right]_{2}$ family in spite of the fact that its structure differs from theirs and belongs to $\alpha$-type [8].

$\left(\mathrm{d}_{8}-\mathrm{ET}\right) \mathrm{HgBr}_{3}$ is isostructural with its protonated analog [15], which contains dimerized stacks of ET molecules. Its spectrum may be considered as intermediate between types 1 and 2, which may be partially due to $1: 1$ composition. 


\section{Acknowledgment}

This work is supported by the Russian Foundation of Fundamental Investigations, project $N$ 93-03-4531.

\section{References}

[1] K. Yamaji, Solid State Commun. 61, 413 (1987).

[2] J.C.R. Faulhaber, D.Y.K. Ko, P.R. Briddon, Synth. Met. 60, 227 (1993).

[3] R.N. Lyubovskaya, E.I. Zhilyaeva, S.I. Pesotskii, L.O. Atovmyan, O.A. Dyachenko, T.G. Takhirov, Pis'ma Zh. Eksp. Teor. Fiz. 46, 149 (1987).

[4] O.A. Dyachenko, V.V. Gritsenko, Sh.G. Mkoyan, G.V. Shilov, L.O. Atovmyan, Izv. AN SSSR Ser. Khim., 2062 (1991).

[5] T.G. Takhirov, O.N. Krasochka, O.A. Dyachenko, L.O. Atovmyan, M.Z. Aldoshina, L.M. Goldenberg, R.N. Lyubovskaya, V.A. Merzhanov, R.B. Lyubovskii, Mol. Cryst. Liq. Cryst. 185, 215 (1990).

[6] O.A. Dyachenko, V.V. Gritsenko, G.V. Shilov, R.N. Lyubovskaya, R.B. Lyubovskii, Izv. AN SSSR Ser. Khim., 1994, in press.

[7] R.N. Lyubovskaya, O.A. Dyachenko, R.B. Lyubovskii, Synth. Met. 55-57, 2459 (1993).

[8] O.A. Dyachenko, V.V. Gritsenko, G.V. Shilov, N.P. Karpova, R.N. Lyubovskaya, Synth. Met., in press.

[9] G. Sekretarchyk, A. Graja, J. Pichet, R.N. Lyubovskaya, R.B. Lyubovskii, J. Phys. (France) 49, 653 (1988).

[10] M.G. Kaplunov, R.N. Lyubovskaya, M.Z. Aldoshina, Yu.G. Borodko, Phys. Status Solidi A 104, 833 (1987).

[11] R.M. Vlasova, S.Ya. Priev, V.N. Semkin, R.N. Lyubovskaya, E.I. Zhilyaeva, E.B. Yagubskii, Synth. Met. 48, 129 (1992).

[12] M.G. Kaplunov, N.D. Kushch, E.B. Yagubskii, Phys. Status Solidi A 110, K111 (1988).

[13].K. Kornelsen, J.E. Eldridge, H.H. Wang, J.M. Williams, Phys. Rev. B 44, 5235 (1991).

[14] M.G. Kaplunov, R.N. Lyubovskaya, J. Phys. I (France) 2, 1811 (1992).

[15] T. Mori, P. Wang, K. Tamaeda, T. Enoki, H. Inokuchi, Solid State Commun. 64, 733 (1987). 